\title{
Is there any benefit to particles over photon radiotherapy?
}

\author{
Maria E Goossens ${ }^{1}$, Marc Van den Bulcke ${ }^{1}$, Thierry Gevaert ${ }^{2}$, Lydie Meheus ${ }^{3}$, Dirk Verellen ${ }^{2,4,5}$, Jean-Marc Cosset ${ }^{6}$ and Guy Storme ${ }^{2}$ \\ ${ }^{1}$ Cancer Centre, Sciensano (Scientific Institute of Public Health), 1050 Brussels, Belgium \\ ${ }^{2}$ Department of Radiotherapy, University Hospital Brussels, Vrije Universiteit Brussel, 1050 Brussel, Belgium \\ ${ }^{3}$ The Anticancer Fund, Reliable Cancer Therapies, Strombeek-Bever, 1853, Belgium \\ ${ }^{4}$ Iridium Kankernetwerk Antwerp, Belgium \\ ${ }^{5}$ Faculty of Medicine and Pharmacy, Vrije Universiteit Brussel, 1050 Brussel, Belgium \\ ${ }^{6}$ Centre de Radiothérapie Charlebourg, Groupe Amethyst, 65, Avenue Foch, 92250 La Garenne-Colombes, France
}

\begin{abstract}
Particle, essentially, proton radiotherapy (RT) could provide some benefits over photon RT, especially in reducing the side effects of RT. We performed a systematic review to identify the performed randomised clinical trials (RCTs) and ongoing RCTs comparing particle RT with photon therapy. So far, there are no results available from phase 3 RCTs comparing particle RT with photon therapy. Furthermore, the results on side effects comparing proton and carbon ion beam RT with photon RT do vary. The introduction of new techniques in photon RT, such as image-guided RT (IGRT), intensity-modulated RT (IMRT), volumetric arc therapy (VMAT) and stereotactic body RT (SBRT) was already effective in reducing side effects. At present, the lack of evidence limits the indications for proton and carbon ion beam RTs and makes the particle RT still experimental.
\end{abstract}

Keywords: hadron, particles radiotherapy, proton, carbon ion beam, cancer

\section{Introduction}

Radiotherapy (RT) after surgery is the second main treatment in solid tumours and far in front of systemic treatment [1]. The use of modern RT with image-guided RT (IGRT), intensity-modulated RT (IMRT), volumetric arc therapy (VMAT) and stereotactic body RT (SBRT) drastically decreased the side effects [2, 3]. In the continuous process for improvement, it was suggested that proton therapy, due to its Bragg peak, and carbon ions, due to the Bragg peak and to a higher radiobiologic effect (RBE), could have a promising future and become the best practice in radiotherapy. Randomised clinical trials (RCTs) are the gold standard to compare the effectiveness of one therapy over another [4]. Observational studies can only provide some indications about possible advantages from one therapy compared to another. The recent health technological assessment (HTA) report in Belgium [5] could not show any advantage for proton therapy over photon therapy. The Ludwig Boltzmann Institute published a recent systematic review for carbon ion beam RT [6]. They concluded that 'carbon ion beam RT (CIRT) can be described as a potentially less invasive cancer treatment due to its physical properties. Due to the lack of controlled trials, no conclusions may be drawn on the comparative effectiveness of CIRT when compared to conventional photon therapy.
Correspondence to: Maria E Goossens Email: maria.goossens@sciensano.be

ecancer 2019, 13:982

https://doi.org/10.3332/ecancer.2019.982

Published: 09/12/2019

Received: 29/09/2019

Publication costs for this article were supported by ecancer (UK Charity number 1176307).

Copyright: (c) the authors; licensee ecancermedicalscience. This is an Open Access article distributed under the terms of the Creative Commons Attribution License (http:// creativecommons.org/licenses/by/3.0), which permits unrestricted use, distribution, and reproduction in any medium, provided the original work is properly cited. 
As of today, CIRT must be considered as experimental treatment' [6]. We reviewed the literature to identify the results from more recent RCTs on particle RT or ongoing trials.

\section{Method}

Because of the high quality and the extensiveness of both the Belgian HTA report [5] and the systematic review of the Ludwig Boltzmann Institute [6], we chose to update these two reports. The Belgian HTA report closed its search in July 2018, the review on CIRT was closed in August 2017. Therefore, we reviewed the literature for systematic reviews and primary studies comparing particle RT with photon therapy in the databases Medline, EMBASE and Cochrane Library since the closing search dates. Single-arm studies are not included in this study. For CIRT, we searched between September 2017 and February 2019; for proton therapy, we searched between August 2018 and February 2019.

\section{Results}

We could identify some new observational studies comparing a photon with particle therapy (Figure 1). The overall survival (OS) in breast cancer patients was assessed using the US National Cancer Database between 2004 and 2014. The OS of patients that received proton therapy was not statistically significantly longer than those that received photon therapy [Hazard ratio (HR) 0.85 ( $95 \%$ Confidence interval (Cl) 0.68-1.07)] [7].

The preliminary results of a study in non-small cell lung cancer with underlying idiopathic pulmonary fibrosis showed a tendency of non-statistically significant better survival compared to X-ray $(p=0.08)$ for patients treated with proton therapy, especially in subgroups of GAP stages II and III at Samsung Medical Center in Korea [8]. In unresectable hepatocellular carcinoma, proton RT was associated with improved survival, which may be driven by decreased incidence of post-treatment liver decompensation [Adjusted hazard ratio (AHR) $=0.47$ $(95 \% \mathrm{Cl} 0.27-0.82)][9]$.

Proton therapy in patients with chordomas and chondrosarcomas was associated with improved OS at 5 years, respectively, $100 \%$ versus $34.1 \%(p=0.03)$ and $75.0 \%$ versus $19.1 \%(p=0.05)$ using the US National Cancer Database for the years 2003-2014 [10]. A meta-analysis showed that particle therapy was more effective following surgery for chordoma than conventional RT with higher percentages of survival after 10 years for proton therapy [60\% (95\% Cl, 43\%-77\%)] and CIRT [45\% (95\% Cl, 36\%-55\%)] [11].

Proton therapy is associated with improved OS [HR $0.47(95 \% \mathrm{Cl} 0.38-0.58)]$ compared to photon RT for patients with primary gliomas in the US National Cancer Database [12].

Consecutive patients with oesophageal cancer of the University of Texas MD Anderson Cancer Center receiving proton beam therapy (PBT) were compared with patients receiving intensity-modulated radiation therapy (IMRT). IMRT compared to proton therapy was associated with significantly worse OS [HR 1.45 (95\% Cl 1.09-1.94)] and worse progression-free survival [HR 1.56 (95\%Cl 1.19-2.05)] [13]. Shiraishi et al [14] performed a propensity matched-based study on key clinical variables in the same institution and found that PBT is associated with significant risk reduction in grade 4 lymphopenia during neoadjuvant chemoradiation therapy in oesophageal cancer.

A recent systematic review for intracranial benign tumours considers proton therapy as safe [15].

The overview of recently published included non-randomised comparative studies is presented in Table 1.

There are still no results available from RCTs. A review of clinicaltrial.gov in 2018 did not show any phase 3 RCT for carbon ion radiation therapy [16]. On the other side, there are several initiatives at a European level promoting research on particle therapy. The European particle therapy network (EPTN) creates a firm basis for evidence-based particle therapy at the European level. To achieve this, a work package will set up a worldwide unique prospective data registration programme for nine different tumour sites. Such a programme will provide more insights into the current practice across all European particle therapy centres and into the results of particle therapy with regard to radiationinduced toxicity and efficacy in terms of local control and survival $[17,18]$. The European network for light ion hadron therapy (ENLIGHT) is another initiative related to hadron therapy $(\mathrm{HT})$, and focuses on patient selection, clinical trials, technology, radiobiology, imaging and health economics [19]. Another European project summarises the data on carbon ion therapy [20]. Different evidence-based clinical trial strategies can be applied to investigate whether the use of protons over photons is justified: the choice of trial design depends on several factors, such as the primary study objective (efficacy versus prevention), the availability of high quality multivariable normal tissue complication probability (NTCP)-models, financial resources and national reimbursement policies [21]. 


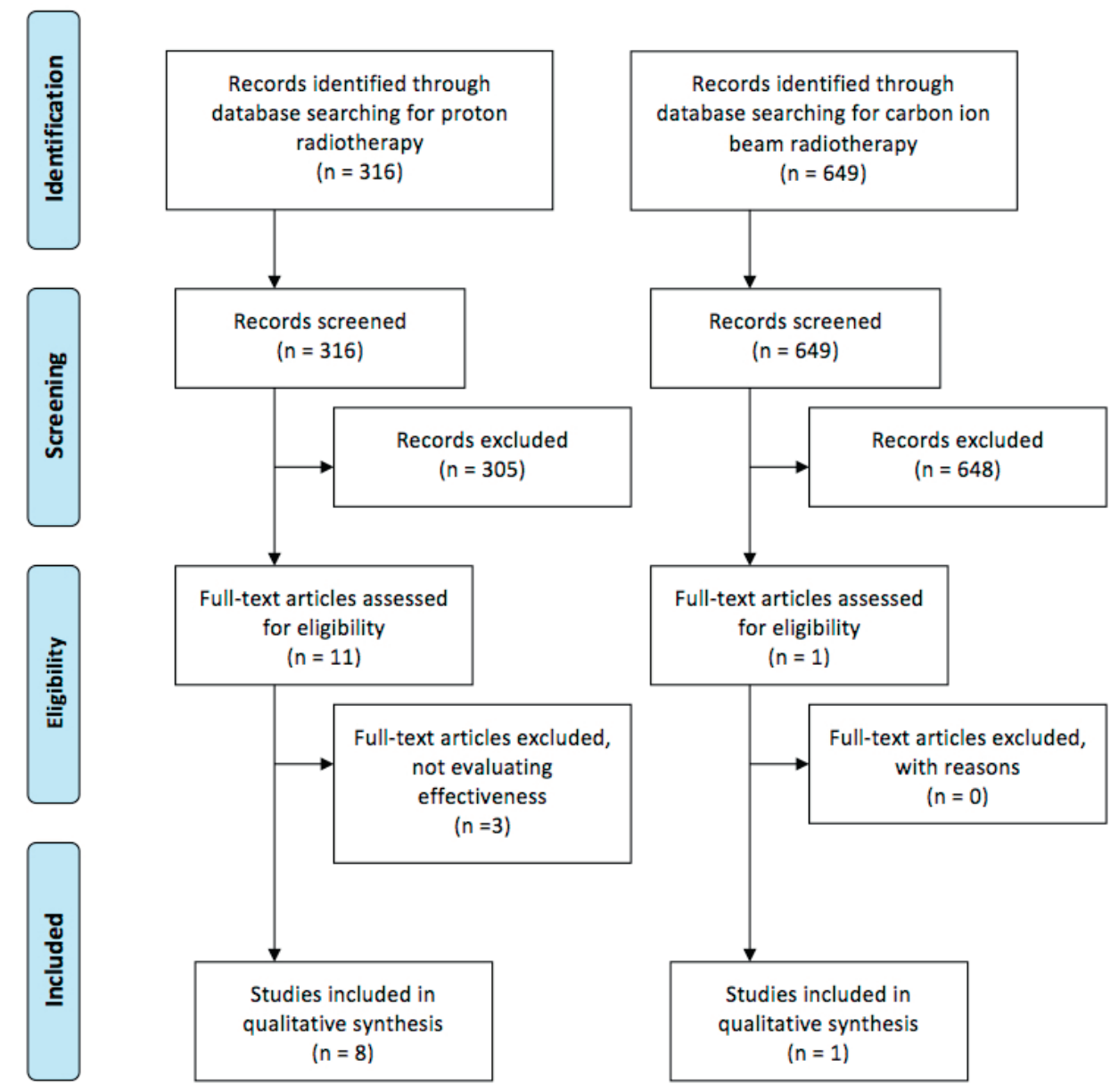

Figure 1. Flow diagram of the published literature stratified for proton and CIRT.

We could identify seven ongoing phase 3 clinical trials on clinicaltrial.gov (Table 2):

- Radiation therapy with protons or photons in treating patients with liver cancer (ClinicalTrials.gov identifier: NCT03186898)

- Trial of proton versus carbon ion radiation therapy in patients with low and intermediate grade chondrosarcoma of the skull base (CSP12C) (ClinicalTrials.gov identifier: NCT01182753)

- Trial of proton versus carbon ion radiation therapy in patients with chordoma of the skull base (HIT-1) (ClinicalTrials.gov identifier: NCT01182779)

- Comparing proton therapy to photon radiation therapy for oesophageal cancer (ClinicalTrials.gov identifier: NCT03801876)

- Comparing photon therapy to proton therapy to treat patients with lung cancer (ClinicalTrials.gov identifier: NCT01993810)

- Randomised carbon ions versus standard RT for radioresistant tumours (https://clinicaltrials.gov/show/nct02838602, 2016 added to CENTRAL: 31 May, 2018 | 2018 Issue 5 NCT02838602)

- Randomised trial of intensity-modulated PBT (IMPT) versus intensity-modulated photon therapy (IMRT) for the treatment of oropharyngeal cancer of the head and neck (NCT01893307) [22]. 
Table 1. Overview of the included comparative studies.

\begin{tabular}{|c|c|c|c|c|c|c|}
\hline Author & Data source, country & Indication & $N$ & Comparison & Reported outcome & Results $(95 \% \mathrm{Cl})$ \\
\hline Chowdhary et al [7] & $\begin{array}{l}\text { National Cancer Database, } \\
\text { USA }\end{array}$ & Breast cancer & $\begin{array}{c}871 \\
723,621\end{array}$ & $\begin{array}{l}\text { Proton RT } \\
\text { Photon RT }\end{array}$ & Overall survival & $0.85(0.68-1.07)$ \\
\hline Kim et al [8] & $\begin{array}{l}\text { Samsung Medical Center, } \\
\text { South Korea }\end{array}$ & Non-small cell lung cancer & $\begin{array}{c}8 \\
22\end{array}$ & $\begin{array}{l}\text { Proton RT } \\
\text { Photon RT }\end{array}$ & 1-Year survival & $\begin{array}{c}50 \text { versus } 26.4 \% \\
\quad(p=0.08)\end{array}$ \\
\hline Sanford et al [9] & $\begin{array}{l}\text { Massachusetts General } \\
\text { Hospital, USA }\end{array}$ & Hepatocellular carcinoma & $\begin{array}{l}49 \\
84\end{array}$ & $\begin{array}{l}\text { Proton RT } \\
\text { Photon RT }\end{array}$ & Overall survival & $0.47(0.27-0.82)$ \\
\hline \multirow[t]{2}{*}{ Palm et al [10] } & \multirow[t]{2}{*}{$\begin{array}{l}\text { National Cancer Database, } \\
\text { USA }\end{array}$} & Chordoma & $\begin{array}{l}183 \\
532\end{array}$ & $\begin{array}{l}\text { Proton RT } \\
\text { Photon RT }\end{array}$ & Overall survival & $0.11(0.01-0.82)$ \\
\hline & & Chondrosarcoma & $\begin{array}{c}54 \\
809\end{array}$ & $\begin{array}{l}\text { Proton RT } \\
\text { Photon RT }\end{array}$ & Overall survival & $0.13(0.02-0.96)$ \\
\hline Zhou et al [11] & Meta-analyse, China & Chordoma & & $\begin{array}{l}\text { Photon RT } \\
\text { stereotactic RT } \\
\text { proton RT } \\
\text { carbon ion RT }\end{array}$ & 10-Year survival & $\begin{array}{l}0.21(0.10-0.33) \\
0.40(0.30-0.55) \\
0.60(0.43-0.77) \\
0.45(0.36-0.55)\end{array}$ \\
\hline Jhaveri et al [12] & $\begin{array}{l}\text { National Cancer Database, } \\
\text { USA }\end{array}$ & Primary gliomas & $\begin{array}{c}170 \\
49,405\end{array}$ & $\begin{array}{l}\text { Proton RT } \\
\text { Photon RT }\end{array}$ & Overall survival & $0.66(0.53-0.83)$ \\
\hline \multirow[t]{2}{*}{ Xi et al [13] } & \multirow[t]{2}{*}{$\begin{array}{l}\text { MD Anderson Cancer } \\
\text { Center, USA }\end{array}$} & \multirow[t]{2}{*}{ Oesophageal cancer } & $\begin{array}{l}211 \\
132 \\
\end{array}$ & $\begin{array}{l}\text { IMRT } \\
\text { Proton RT }\end{array}$ & Overall survival & $1.45(1.09-1.94)$ \\
\hline & & & $\begin{array}{l}211 \\
132\end{array}$ & $\begin{array}{l}\text { IMRT } \\
\text { Proton RT }\end{array}$ & $\begin{array}{l}\text { Progression free } \\
\text { interval }\end{array}$ & $1.56(1.19-2.05)$ \\
\hline Shiraishi et al* [14] & $\begin{array}{l}\text { MD Anderson Cancer } \\
\text { Center, USA }\end{array}$ & Oesophageal cancer & $\begin{array}{l}136 \\
136\end{array}$ & $\begin{array}{l}\text { IMRT } \\
\text { Proton RT }\end{array}$ & Grade 4 lymphopenia & $0.29(0.16-0.52)$ \\
\hline
\end{tabular}

* propensity-matched study, IMRT: intensity-modulated radiation therapy

Table 2. Ongoing phase 3 clinical trials on ClinicalTrials.gov on particle radiotherapy.

\begin{tabular}{|c|c|c|c|c|c|c|}
\hline $\begin{array}{l}\text { ClinicalTrials. } \\
\text { gov Identifier }\end{array}$ & Cancer & Intervention & Comparator & Country & $\begin{array}{c}\text { Start date } \\
\text { Estimated end date }\end{array}$ & Primary endpoint \\
\hline NCT03186898 & Liver & Proton RT & Photon RT & USA & $\begin{array}{lc}\text { June } & 2017 \\
\text { August } & 2022\end{array}$ & OS \\
\hline NCT01182753 & Chondro-sarcoma & Carbon ion RT & Proton $\mathrm{RT}^{*}$ & Germany & $\begin{array}{ll}\text { August } & 2010 \\
\text { August } & 2022\end{array}$ & 5-Year LPFS \\
\hline NCT01182779 & Chordoma & Carbon ion RT & Proton $\mathrm{RT}^{*}$ & Germany & $\begin{array}{ll}\text { August } & 2010 \\
\text { August } & 2023\end{array}$ & 8-Year LPFS \\
\hline NCT03801876 & Oesophage & Proton RT & IMRT & USA & $\begin{array}{ll}\text { March } & 2019 \\
\text { February } & 2027\end{array}$ & OS \\
\hline NCT01993810 & Lung & Proton RT & Photon RT & USA & $\begin{array}{l}\text { February } 2014 \\
\text { December } 2020\end{array}$ & OS \\
\hline NCT02838602 & Radio-resistant & Carbon ion RT & $\begin{array}{l}\text { Proton } \mathrm{RT}^{*} \\
\text { IMRT }\end{array}$ & France & $\begin{array}{l}\text { December } 2017 \\
\text { November } 2023\end{array}$ & $\begin{array}{l}5 \text {-Year } \\
\text { PFS }\end{array}$ \\
\hline NCT01893307 & Oro-pharynx & IMPT & IMRT & USA & $\begin{array}{ll}\text { August } & 2013 \\
\text { August } & 2023\end{array}$ & Toxicity \\
\hline
\end{tabular}

RT, radiotherapy; IMRT, Intensity-Modulated Photon Therapy; IMPT, Intensity-Modulated Proton Beam Therapy; OS, overall survival; LPFS, Local-Progression Free Survival; PFS, Progression-Free Survival *reference comparator is proton NOT photon radiotherapy 


\section{Discussion}

While results for particle therapy are still limited to the results of observational studies, there are no results of randomised studies and only a handful of ongoing clinical trials. Most of the trials are superiority trials while the German trial comparing carbon ion RT with proton RT in chondrosarcoma has a non-inferiority design. The lack of results of RCTs is somewhat surprising if we take into account that the first accelerator using protons built primarily for medical use, the Crocker Medical Cyclotron, was completed at Berkeley in 1939 and the first patient was treated in 1954. Regardless of this long track record, today, there is still no clear answer on a possible benefit considering that with modern photon-based approaches such as IGRT, IMRT including VMAT and SBRT dose distributions can be obtained, which challenge the possibilities offered by proton treatment with excellent tumour control and minimal toxicity [3]. Nearly, all newly found retrospective observational studies have reported on OS. Data on toxicity and adverse effect are less likely available in large cancer registries and could only be found in the patient's electronic health record (EHR). Even there, these data are not always structured and so not available for research. Linking structured data of the EHR with existing cancer registries can bridge a gap between daily practice and research [23, 24]. Furthermore, retrospective observational studies suffer from time-related biases [4, 25, 26]. Immortal time bias can be a major issue and is induced in time-fixed cohort analyses which misclassify unexposed time as exposed time [25, 26]. To overcome these biases, randomised trials will almost always be necessary to show whether the hoped-for benefit of a medical intervention exists [4]. Finally, the technological advancement of the photon beam (IMRT, IGRT, SBRT and VMAT) may also influence OS. Depending on the time period comparing proton with photon RT when these newer techniques were not yet available, OS could be better for proton RT. Finally, also the quality of the facility could influence the OS [27].

The RBE of protons is dependent on dose and on the dose fractionation scheme used. A variety of normal tissue and tumour endpoints has been employed to obtain data on RBE in in vivo studies, and it is currently accepted that the RBE value for protons is about 1.1. The major challenge is the inhomogeneity of the tissues and mobility in anatomy causing large variations in tissue density leading to uncertainties in the range of the Bragg peak. These issues need to be addressed in dose calculations and treatment planning, particularly for single field treatments or for distal edges in or close to a critical structure [28]. Recent developments focus on robust treatment planning to compensate for both random (unpredictable) and systematic variables that might influence the dose deposition accuracy [29]. The advantages of proton treatment get lost for the fact that particle treatment is unforgiving for these uncertainties, whereas photons by nature are more robust and forgiving for these issues in real-life clinical situations. Nevertheless, even if protons reduce the low-dose bath, the conformity of the high-dose region immediately adjacent to the target is superior for IMRT [30]. Moreover, we must keep in mind that the neutron-scattered dose is much higher with 'passive' (scattering) proton technology than with 'active' (pencil beam scanning) proton techniques (PBS-PT) [31]. This PBS PT, particularly intensity-modulated PT, represents the latest advanced PT technology for treating cancers, including thoracic malignancies. However, implementing PBS-PT for moving targets has several additional technical challenges compared with intensity modulated photon radiation therapy or passive scattering PT. Four-dimensional computed tomography-based motion management and robust optimisation and evaluation are crucial for minimising uncertainties associated with beam range and organ motion. Active motion management (e.g. breath-hold), beam gating, rescanning, tracking or adaptive planning may be needed for cases involving significant motion or changes in motion or anatomy over the course of treatment. [32]. Current risk models used with carefully obtained dose distributions predict a second cancer risk reduction for active protons versus photons, but a more or less constant risk of passive protons versus photons [31], while the potential risks of second cancers from scattered proton RT for childhood cancers may cause concern [33]. On the other hand, a recent prospective randomised comparative trial found no differences between intensity-modulated photon therapy (IMRT) and passive scattering proton RT in patients with non-small cell lung cancer [34], and the dose response (the slope of linear ${ }^{18} \mathrm{~F}$-FDG-uptake) did not differ significantly between the two modalities [35].

Standard indications for proton RT are melanoma of the eye and uveal tract, brain tumours, certain head and neck tumours and tumours of the base of the skull and of the spine [36, 37]. The benefit could be explained by using the former imaging localisation and fixation of those locations [36, 38]. With exception of the aforementioned pathologies, which in many cases can be challenged with new developments in photon treatment [e.g. high-precision, high doses per fraction treatments such as stereotactic radiosurgery (SRS) and SBRT], there are no other clear indications that favour proton treatment, today. A recent study [39] reviewed the literature for malignancies in children. This review includes also the results from the Belgian HTA report on Hadron RT for children [40] and concluded that while results from phase 3 RCTs are not yet available in paediatric malignancies, clinical outcomes for PT should be favourable with an improved quality of life (QoL), 
organ function and development and with a reduction in the risk of second malignant neoplasms. On the other hand, ototoxicity was not reduced in children with medulloblastoma [41]. Based on limited data, PBT provides favourable QoL and patient-reported outcome (PRO) profiles for the select brain, head/neck, lung and paediatric cancers [42].

We observe that for proton centres to be financially viable, in addition to the 'commonly accepted indications' also 'conditions of possible benefit' such as tumours of prostate and lung are considered for treatment [43]. While the 'commonly accepted indications' decrease over the years (18.7\% in 2006 to $10.6 \%$ in 2009), the 'conditions of possible benefit' increase from $80 \%$ to $89.4 \%$ during the same years [43]. As such, the cost of cancer care increases without proof of a real benefit. This is also the case for systemic cancer treatment, which is close to $50 \%$ of the financial cost with an improvement in outcome (survival) between $2.5 \%$ and $10.0 \%$ [44]. A recent study calculated that the overall incremental cost-effectiveness ratio (ICER) for skull base chordoma was €8,855.76/QALY [45].

In The Netherlands, the proton project has a model-based approach based on NTCP for selecting patients, which should be effective as well in outcome as for reducing side effects [46]. After a long period of societal discussion, proton therapy became available in The Netherlands in 2018. This therapy was introduced to The Netherlands in a unique manner. The proton centres have been given permission to treat a maximum of 2,200 patients per year, 4.4\% of the total number of patients who receive RT [47]. In Belgium, end-2019, it will be possible for patients to have particle RT at the university hospital of Leuven. Approximately, 100-200 patients a year will be eligible for proton therapy. This number could increase in the future if clinical-scientific trials can determine new indications for proton therapy [48]. Proton therapy will be a reality in Norway from 2023 [15].

Finally, while the level of evidence is still low for proton therapy, the information found on the websites of the proton therapy centres is not always in line with the accepted guidelines and consensus opinion [49].

The technical, radiobiological and financial problems are still more important and complicated with carbon ions. As stated above, no results of any RCT are available today, and ongoing trials comparing carbon ions with protons are limited. The radiobiology of carbon ions is still more complex, with a higher RBE, which varies by a large amount along the Bragg peak. Moreover, the increase in RBE with depth in the stopping region of the particles (the 'tail'), already mentioned for protons, may pose still more serious complications with carbon ions. Last but not least, the radioprotection problems raised by the use of carbon ions led the International Commission on Radiological Protection (ICRP) to release its publication 127 in 2014 [50]. Finally, the cost of carbon ion facilities exceeds by large the one of a proton centre, and by several orders of magnitude the cost of a modern RT centre [51].

\section{Conclusion}

So far, there are no results available from phase 3 RCTs, neither on side effects nor on outcome comparing particle RT with photon therapy. The introduction of new techniques in photon RT such as IGRT, IMRT, VMAT and SBRT has already proven to be effective in reducing side effects. The lack of evidence limits the indications for proton RT and makes proton RT still experimental. While waiting for the results of the ongoing randomised trials including trials comparing proton RT with IMRT, proton RT should use the best available technique (PSB) and be strictly reserved for selected patients. For carbon ions, the present lack of evidence limits the indications and make this therapy still experimental.

\section{Conflicts of interest}

The authors declare that they have no conflicts of interest.

\section{Funding statement}

None to declare. 


\section{Acknowledgments}

We wish to thank Frank Hulstaert and Roos Leroy from the Belgian Health Care Knowledge Centre (KCE) for their review of the manuscript.

\section{References}

1. Morgan G, Ward R, and Barton M (2004) The contribution of cytotoxic chemotherapy to 5-year survival in adult malignancies Clin Oncol (R Coll Radiol) 16(8) 549-560 https://doi.org/10.1016/j.clon.2004.06.007

2. Deng X, Han C, and Chen S, et al (2017) Dosimetric benefits of intensity-modulated radiotherapy and volumetric-modulated arc therapy in the treatment of postoperative cervical cancer patients J Appl Clin Med Phys 18(1) 25-31 PMID: 28291936 PMCID: 5689869

3. Verellen D, De Ridder M, and Linthout N, et al (2007) Innovations in image-guided radiotherapy Nat Rev Cancer 7(12) 949-960 https:// doi.org/10.1038/nrc2288 PMID: 18034185

4. Vandenbroucke JP (2009) The HRT controversy: observational studies and RCTs fall in line Lancet 373(9671) 1233-1235 https://doi. org/10.1016/S0140-6736(09)60708-X PMID: 19362661

5. Vlayen J, García Fernández L, and Boterberg T, et al (2019) Proton beam therapy in adults KCE Reports (Brussels: Belgian Health Care Knowledge Centre (KCE))

6. Goetz G and Mitic M (2018) Carbon ion beam radiotherapy (CIRT) for cancer treatment: a systematic review of effectiveness and safety for 12 oncologic indications Vienna: Ludwig Boltzmann Institute for Health Technology Assessment. HTAProject Report no. 101

7. Chowdhary M, Lee A, and Gao S, et al (2018) Is proton therapy a "pro" for breast cancer? A comparison of proton vs. non-proton radiotherapy using the national cancer database Front Oncol 8678 https://doi.org/10.3389/fonc.2018.00678

8. Kim H, Pyo H, and Noh JM, et al (2019) Preliminary result of definitive radiotherapy in patients with non-small cell lung cancer who have underlying idiopathic pulmonary fibrosis: comparison between X-ray and proton therapy Radiat Oncol 14(1) 19 https://doi. org/10.1186/s13014-019-1221-4 PMID: 30691496 PMCID: 6348683

9. Sanford NN, Pursley J, and Noe B, et al (2019) Protons vs photons for unresectable hepatocellular carcinoma: liver decompensation and overall survival proton radiotherapy for hepatocellular carcinoma Int J Radiat Oncol Biol Phys 105(1) 64-72 https://doi.org/10.1016/j. ijrobp.2019.01.076 PMID: 30684667

10. Palm RF, Oliver DE, and Yang GQ, et al (2019) The role of dose escalation and proton therapy in perioperative or definitive treatment of chondrosarcoma and chordoma: an analysis of the National Cancer Data Base Cancer125(4) 642-651 https://doi.org/10.1002/ cncr.31958 PMID: 30644538

11. Zhou J, Yang B, and Wang X, et al (2018) Comparison of the effectiveness of radiotherapy with photons and particles for chordoma after surgery: a meta-analysis World Neurosurg 117 46-53 https://doi.org/10.1016/j.wneu.2018.05.209 PMID: 29879512

12. Jhaveri J, Cheng E, and Tian S, et al (2018) Proton vs. photon radiation therapy for primary gliomas: an analysis of the National Cancer Data Base Fron Oncol 8440 https://doi.org/10.3389/fonc.2018.00440

13. Xi M, Xu C, and Liao Z, et al (2017) Comparative outcomes after definitive chemoradiotherapy using proton beam therapy versus intensity modulated radiation therapy for esophageal cancer: a retrospective, single-institutional analysis Int J Radiat Oncol Biol Phys 99(3) 667-676 https://doi.org/10.1016/j.ijrobp.2017.06.2450 PMID: 29280461 
14. Shiraishi $\mathrm{Y}$, Fang $\mathrm{P}$, and $\mathrm{Xu} \mathrm{C}$, et al (2018) Severe lymphopenia during neoadjuvant chemoradiation for esophageal cancer: a propensity matched analysis of the relative risk of proton versus photon-based radiation therapy Radiother Oncol 128(1) 154-160 https://doi. org/10.1016/j.radonc.2017.11.028 PMCID: 5999560

15. Lesueur P, Calugaru V, and Nauraye C, et al (2019) Proton therapy for treatment of intracranial benign tumors in adults: a systematic review Cancer Treat Rev 72 56-64 https://doi.org/10.1016/j.ctrv.2018.11.004

16. Lazar AA, Schulte R, and Faddegon B, et al (2018) Clinical trials involving carbon-ion radiation therapy and the path forward Cancer 124(23) 4467-4476 https://doi.org/10.1002/cncr.31662 PMID: 30307603 PMCID: 6540799

17. Langendijk JA, Orecchia R, and Haustermans K, et al (2018) Prospective data registration and clinical trials for particle therapy in Europe Radiother Oncol 128(1) 9-13 https://doi.org/10.1016/j.radonc.2018.06.001 PMID: 30056852

18. Dosanjh M, Jones B, and Pawelke J, et al (2018) Overview of research and therapy facilities for radiobiological experimental work in particle therapy. Report from the European Particle Therapy Network radiobiology group Radiother Oncol 128(1) 14-18 https://doi. org/10.1016/j.radonc.2018.03.008 PMID: 29703500

19. Dosanjh M, Amaldi U, and Mayer R, et al (2018) ENLIGHT: European network for light ion hadron therapy Radiother Oncol 128(1) 76-82 https://doi.org/10.1016/j.radonc.2018.03.014 PMID: 29625810

20. Vogin G, Wambersie A, and Koto M, et al (2019) A step towards international prospective trials in carbon ion radiotherapy: investigation of factors influencing dose distribution in the facilities in operation based on a case of skull base chordoma Radiat Oncol 14(1) 24 https://doi.org/10.1186/s13014-019-1224-1 PMID: 30709366 PMCID: 6359776

21. Langendijk JA, Boersma LJ, and Rasch CRN, et al (2018) Clinical trial strategies to compare protons with photons Semin Radiat Oncol 28(2) 79-87 https://doi.org/10.1016/j.semradonc.2017.11.008 PMID: 29735194

22. Randomized Trial of Intensity-Modulated Proton Beam Therapy (IMPT) Versus Intensity-Modulated Photon Therapy (IMRT) for the Treatment of Oropharyngeal Cancer of the Head and Neck [https://clinicaltrialsgov/ct2/show/NCT01893307?id=NCT01993810+OR+ NCT01893307+OR+NCT00002703\&draw=2\&rank=2\&load=cart] Date accessed: 05/02/2018

23. Claire Simon K, Hentati A, and Rubin S, et al (2018) Successful utilization of the EMR in a multiple sclerosis clinic to support quality improvement and research initiatives at the point of care Mult Scler J Exp Transl Clin 4(4) 2055217318813736 PMID: 30559971 PMCID: 6293369

24. Linkov F, Silverstein JC, and Davis M, et al (2018) Integration of cancer registry data into the text information extraction system: leveraging the structured data import tool J Pathol Inform 947 https://doi.org/10.4103/jpi.jpi_38_18

25. Suissa S and Azoulay L (2012) Metformin and the risk of cancer: time-related biases in observational studies Diabetes care 35(12) 2665-2673 https://doi.org/10.2337/dc12-0788 PMID: 23173135 PMCID: 3507580

26. Goossens ME, Buntinx F, and Zeegers MP, et al (2015) Influence of metformin intake on the risk of bladder cancer in type 2 diabetes patients BrJ Clin Pharmacol 80(6) 1464-1472 https://doi.org/10.1111/bcp.12740 PMID: 26256299 PMCID: 4693487

27. Pfister DG, Rubin DM, and Elkin EB, et al (2015) Risk adjusting survival outcomes in hospitals that treat patients with cancer without information on cancer stage JAMA Oncol 1(9) 1303-1310 https://doi.org/10.1001/jamaoncol.2015.3151 PMID: 26448610 PMCID: $\underline{5038982}$

28. Paganetti H (2014) Relative biological effectiveness (RBE) values for proton beam therapy. Variations as a function of biological endpoint, dose, and linear energy transfer Phys Med Biol 59(22) R419-R472 https://doi.org/10.1088/0031-9155/59/22/R419 PMID: 25361443

29. Barragan Montero A (2017) Robust, accurate, and patient specific proton therapy (Thesis) Université Catholique de Lille, France 
30. Mohan R, Mahajan A, and Minsky BD (2013) New strategies in radiation therapy: exploiting the full potential of protons Clin Cancer Res 19(23) 6338-6343 https://doi.org/10.1158/1078-0432.CCR-13-0614 PMID: 24077353 PMCID: 4547528

31. Schneider $U$ and Halg R (2015) The impact of neutrons in clinical proton therapy Fron Oncol 5235

32. Chang JY, Zhang X, and Knopf A, et al (2017) Consensus guidelines for implementing pencil-beam scanning proton therapy for thoracic malignancies on behalf of the PTCOG thoracic and lymphoma subcommittee Int J Radiat Oncol Biol Phys 99(1) 41-50 https://doi. org/10.1016/j.ijrobp.2017.05.014 PMID: 28816159

33. Trott KR (2017) Special radiobiological features of second cancer risk after particle radiotherapy Phys Med 42 221-227 https://doi. org/10.1016/j.ejmp.2017.05.002 PMID: 29103987

34. Yang P, Xu T, and Gomez DR, et al (2019) Patterns of local-regional failure after intensity modulated radiation therapy or passive scattering proton therapy with concurrent chemotherapy for non-small cell lung cancer Int J Radiat Oncol Biol Phys 103(1) 123-131 https://doi.org/10.1016/j.ijrobp.2018.08.031

35. Shusharina N, Liao Z, and Mohan R, et al (2018) Differences in lung injury after IMRT or proton therapy assessed by (18)FDG PET imaging Radiother Oncol 128(1) 147-153 https://doi.org/10.1016/j.radonc.2017.12.027 PMID: 29352608

36. UnitedHealthcare (2019, effective date: 1 January 2019) Proton Beam Radiation Therapy Policy Number: 2019T0132AA [https://www. uhcprovider.com/content/dam/provider/docs/public/policies/comm-medical-drug/proton-beam-radiation-therapy.pdf] Date accessed: 26/01/2019

37. Annemans L, Colardyn F, and De Croock R, et al (2013) Feasibility Study of a Hadron Therapy Centre in Belgium (Brussel: ASP)

38. Suit HD, Goitein M, and Tepper J, et al (1975) Explorotory study of proton radiation therapy using large field techniques and fractionated dose schedules Cancer 35(6) 1646-1657 PMID: 807316

39. Weber DC, Habrand JL, and Hoppe BS, et al (2018) Proton therapy for pediatric malignancies: fact, figures and costs. A joint consensus statement from the pediatric subcommittee of PTCOG, PROS and EPTN Radiother Oncol 128(1) 44-55 https://doi.org/10.1016/j. radonc.2018.05.020 PMID: 29937209

40. Leroy R, Benahmed N, and Hulstaert F, et al (2015) Hadron therapy in children - an update of the scientific evidence for 15 paediatric cancers. Health Technology Assessment (HTA) Brussels: Belgian Health Care Knowledge Centre (KCE), Report no.: 235

41. Paulino AC, Mahajan A, and Ye R, et al (2018) Ototoxicity and cochlear sparing in children with medulloblastoma: proton vs. photon radiotherapy Radiother Oncol 128(1) 128-132 https://doi.org/10.1016/j.radonc.2018.01.002 PMID: 29373195

42. Verma V, Simone CB 2nd, and Mishra MV (2018) Quality of life and patient-reported outcomes following proton radiation therapy: a systematic review J Natl Cancer Inst 110(4) https://doi.org/10.1093/jnci/djx208

43. Jarosek S, Elliott S, and Virnig BA (2011) Proton Beam Radiotherapy in the U.S. Medicare Population: Growth in Use Between 2006 and 2009: Data Points \# 10 (Rockville, Maryland: Data Points Publication Series)

44. Storme G, Dhaese S, and Corens D, et al (2016) The cost of cancer care is not related to its outcomes Ecancermedicalscience 10 687 https://doi.org/10.3332/ecancer.2016.687 PMID: 27994643 PMCID: 5130330

45. Sprave T, Verma V, and Sterzing F, et al (2018) Cost-effectiveness of carbon ion radiation therapy for skull base chordoma utilizing long-term (10-year) outcome data Anticancer Res 38(8) 4853-4858 https://doi.org/10.21873/anticanres.12797 PMID: 30061259

46. Widder J, van der Schaaf A, and Lambin P, et al (2016) The quest for evidence for proton therapy: model-based approach and precision medicine Int J Radiat Oncol Biol Phys 95(1) 30-36 https://doi.org/10.1016/j.ijrobp.2015.10.004

47. Boersma LJ, van Vulpen M, and Rasch CRN, et al (2018) Proton therapy centres opened; what next? Ned Tijdschr Geneeskd 162 
48. Leuven K (2019) First Belgian Centre For Proton Therapy in the University Hospitals Leuven [https://gbiomed.kuleuven.be/english/ biomedia/centre-for-proton-therapy]

49. Corkum MT, Liu W, and Palma DA, et al (2018) Online advertising and marketing claims by providers of proton beam therapy: are they guideline-based? Radiat Oncol 13(1) 43 https://doi.org/10.1186/s13014-018-0988-z PMID: 29544511 PMCID: 5856220

50. Yonekura Y, Tsujii H, and Hopewell JW, et al (2014) ICRP publication 127: radiological protection in ion beam radiotherapy Ann ICRP 43(4) 5-113 https://doi.org/10.1177/0146645314559144

51. Peeters A, Grutters JP, and Pijls-Johannesma M, et al (2010) How costly is particle therapy? Cost analysis of external beam radiotherapy with carbon-ions, protons and photons Radiother Oncol 95(1) 45-53 https://doi.org/10.1016/j.radonc.2009.12.002 PMID: 20106540 